\title{
Healthcare Experiences of Transgender People of Color
}

\author{
Susanna D. Howard, $M D^{7}$, Kevin L. Lee, MA², Aviva G. Nathan, MPH', \\ Hannah C. Wenger, $\mathrm{MD}^{7}$, Marshall H. Chin, $M D \mathrm{MPH}^{\prime}$, and Scott C. Cook, $P h D^{7}$ \\ ', Section of General Internal Medicine, University of Chicago, Chicago, IL, USA; ${ }^{2}$, Department of Urban Studies and Planning, Massachusetts \\ Institute of Technology, Cambridge, MA, USA.
}

\begin{abstract}
BACKGROUND: Transgender people and racial/ethnic minorities separately report poor healthcare experiences. However, little is known about the healthcare experiences of transgender people of color (TPOC), who are both transgender and racial/ethnic minorities.
\end{abstract}

OBJECTIVE: To investigate how TPOC healthcare experiences are shaped by both race/ethnicity and gender identity.

DESIGN AND PARTICIPANTS: Semi-structured, indepth individual interviews $(n=22)$ and focus groups $(2$; $n=17$ total); all taken from a sample of TPOC from the Chicago area. All participants completed a quantitative survey $(n=39)$.

APPROACH: Interviews and focus groups covered healthcare experiences, and how these were shaped by gender identity and/or race/ethnicity. The interviews and focus groups were audio recorded, transcribed verbatim, and imported into HyperRESEARCH software. At least two reviewers independently coded each transcript using a codebook of themes created following grounded theory methodology. The quantitative survey data captured participants' demographics and past healthcare experiences, and were analyzed with descriptive statistics.

KEY RESULTS: All participants described healthcare experiences where providers responded negatively to their race/ethnicity and/or gender identity. A majority of participants believed they would be treated better if they were cisgender or white. Participants commonly cited providers' assumptions about TPOC as a pivotal factor in negative experiences. A majority of participants sought out healthcare locations designated as lesbian, gay, bisexual, and transgender (LGBT)-friendly in an effort to avoid discrimination, but feared experiencing racism there. A minority of participants expressed a preference for providers of color; but a few reported reluctance to reveal their gender identity to providers of their own race due to fear of transphobia. When describing positive healthcare experiences, participants were most likely to highlight providers' respect for their gender identity.

CONCLUSIONS: TPOC have different experiences compared with white transgender or cisgender racial/ethnic minorities. Providers must improve understanding of intersectional experiences of TPOC to improve quality of care.

KEY WORDS: gay and lesbian health; cultural competency; primary care; race and ethnicity; underserved populations.

Received July 27, 2018

Revised December 11, 2018

Accepted April 9, 2019

Published online August 5, 2019

2068
J Gen Intern Med 34(10):2068-74

DOI: $10.1007 / \mathrm{s} 11606-019-05179-0$

(C) Society of General Internal Medicine 2019

\section{INTRODUCTION}

Discrimination and prejudice in healthcare settings against transgender people and racial/ethnic minorities, as separate social groups, are well-documented. ${ }^{1-7}$ While both racial/ ethnic minority and transgender patients disproportionately report negative healthcare experiences compared with their white and cisgender counterparts, respectively, little is known about the healthcare experiences of transgender people of color (TPOC).

The limited literature suggests that individuals who are both transgender and racial/ethnic minorities suffer from poorer health outcomes, compared with their single minority counterparts. ${ }^{8-10}$ For instance, the US Transgender Survey (USTS), a 2015 nationwide survey with 27,715 transgender respondents, illuminates important health inequities. For example, black transgender women reported higher HIV prevalence rates compared with the overall transgender sample, and TPOC reported higher rates of attempted suicide and lack of health insurance. ${ }^{2}$ While the USTS offers write-in responses, it mostly comprises closed-ended questions that limit exploration of how healthcare experiences of TPOC impact their health outcomes.

For instance, an African-American transgender man may experience discrimination based on his race, and be misgendered in an appointment with a white cisgender provider. Uncomfortable in a healthcare location serving a predominately white transgender population, and marginalized in a clinic serving mostly cisgender African-American patients, he might then avoid treatment altogether, thereby resulting in poorer health outcomes. In recognition of these complexities, we take an intersectional approach to the healthcare experiences of TPOC. TPOC do not face systems of oppression in isolation. Rather, they confront the intertwined dynamics of transphobia and racism together. An intersectional approach means examining how their experiences are impacted collectively by their multiple social identities, i.e. race/ethnicity, gender identity, and sexuality. ${ }^{11-15}$

We conducted in-depth individual interviews, focus groups, and a quantitative survey to explore the healthcare 
experiences of TPOC, and how race/ethnicity and gender identity converge to shape their healthcare experiences. We provided space for TPOC to speak for themselves. Our goal is to enhance providers' awareness and understanding of the unique challenges that study participants face in order to improve the quality of care delivered to this underserved population.

\section{METHODS}

\section{Participants and Setting}

Participants were recruited online (Twitter, Facebook), during community events, and at community-based organizations in Chicago, IL, between 2016 and 2017. Participants were English-speaking individuals, 18 years old or older, racial or ethnic minorities, and self-identified their gender as something other than a binary male or female assigned at birth. Participants received a $\$ 40$ cash stipend, which was stated in recruitment materials. This study was approved by the University of Chicago Biological Sciences Division Institutional Review Board.

\section{Data Collection}

We conducted in-person semi-structured individual interviews $(n=22)$ and focus groups ( $2 ; n=17$ total) among racial/ethnic minority transgender and gender non-conforming individuals about their healthcare experiences. Participation in the individual interviews and focus groups was mutually exclusive. Individual interviews ranged between 45 and 60 minutes. Focus groups were approximately 90 minutes each. Trained community members obtained informed consent, and conducted the interviews and focus groups. This study is part of a larger project, Your Voice! Your Health! (http:// chicagodiabetesresearch.org/research/lgbtq-sdm/), focused on improving shared decision making with LGBT racial/ethnic minority patients. ${ }^{13,15-17}$

Participants completed a paper survey prior to each interview, which included questions about participants' demographics, healthcare experiences, and how they chose a healthcare provider. All of the individual interview and focus group participants completed the survey.

The interview guide used for the qualitative interviews consisted of open-ended questions with follow-up probes. The first section of the interview guide asked participants to describe a positive and negative healthcare experience. The second section focused on the impact of gender identity and race on participants' healthcare experience. An example question is: "How does being both transgender and a person of color affect how your providers interact with you?." The third section focused on gathering advice for health providers and how to develop tools to improve healthcare experiences of TPOC. Questions were fieldtested and modified for optimal use.
Due to time constraints, five questions from the individual interview guide were not included in the focus group interview guide, including four related to the impact of gender identity and race on participants' healthcare experience, and one related to advice for providers. The individual interviews and focus groups allowed for cross-validation of emergent themes. ${ }^{18,19}$ While one-on-one interviews allowed participants to share a rich narrative of their own individual experience, focus groups provided a context in which participants could compare their experiences with others, often eliciting consensus of opinion. ${ }^{20}$ To avoid overrepresentation of themes from the focus group setting, the $n$ - or number of participants corroborating a certain theme or concept in our results - only includes the number of individual interview participants.

\section{Data Analysis}

All interviews were audio recorded and transcribed verbatim. Four coders (M.C., S.C., S.H., A.N.) independently reviewed and coded the first five individual interview transcripts, and then met as a group to discuss the coding in order to create one uniform codebook of themes following grounded theory methodology. ${ }^{21,} 22$ The remaining 18 individual interviews and two focus groups were each randomly assigned to two reviewers (M.C., S.C., S.H., K.L., A.N., H.W.) to code the transcripts individually and then resolve the discrepancies to consensus. The coded individual interviews and focus groups were then imported into HyperRESEARCH 3.7.3 software for further analysis. The frequency of codes used was tabulated across all transcripts. Codes that appeared at higher frequencies were then partitioned into subthemes to avoid oversimplification from quantizing qualitative data. ${ }^{19}$ Exceptions or outliers to recurrent themes were also examined in detail, and presented in results to illustrate counterpoints. After preliminary data analysis, results were presented at two separate community forums of LGBT people of color to solicit feedback and validate our interpretation of the data.

The paper survey responses were entered into REDCap electronic data capture tools hosted at the University of Chicago, then subsequently exported into Microsoft Excel 14.4.0 software for calculation of frequencies and percentages. Percentages were determined based on the total number of responses for each particular survey item. For relevant survey items asking for agreement with proposed statements, certain responses (e.g., strongly agree and agree; strongly disagree and disagree) were grouped together in reporting the result.

\section{Basic Terminology}

Gender identity refers to a person's sense of their own gender and is unrelated to sexual orientation. Transgender describes those whose gender identity is different than that typically associated with their assigned sex at birth. Cisgender describes those whose gender identity is typically associated with their assigned sex at birth. Genderqueer is a 
term used by individuals who identity as neither entirely male nor female. ${ }^{1}$ To be clocked refers to being perceived by others as transgender or gender non-conforming. To misgender refers to a situation when the pronouns or other gender-specific words used to refer to a person do not align with their gender identity. Transphobia refers to a range of negative attitudes and behaviors towards or discrimination against members of the transgender community. Sexual orientation is unrelated to gender identity and is the confluence of three factors that may or may not align; how a person identifies or describes their sexuality, the genders of the people to whom they are romantically and sexually attracted, and the genders of the people with whom they have sex. Lesbian, gay, and bisexual describe a person's sexual orientation, and include people who are either exclusively or non-exclusively attracted to individuals of the same sex. ${ }^{11}$ Homophobia refers to a range of negative attitudes and behaviors towards or discrimination against members of the lesbian, gay, bisexual, and queer community. It is based on perceived or actual sexual orientation and thus can be directed at transgender individuals.

\section{RESULTS Participant Characteristics}

Table 1 shows the demographics of both the individual interview $(n=22)$ and focus group $(n=17)$ participants that were collected as part of the quantitative survey. A majority of participants $(71 \%)$ were 18 to 34 years old with an average age of 32 years. Sixty-seven percent participants identified as transgender women, followed by $15 \%$ as transgender men, $15 \%$ as genderqueer, and $3 \%$ as other gender identities. Black or African-American participants (54\%) were the most heavily represented racial/ethnic group. Sexual orientation of participants varied with $33 \%$ identifying as bisexual, pansexual, or queer, $31 \%$ as straight/heterosexual, $23 \%$ as gay/same-gender loving man, $10 \%$ as other, and $3 \%$ as lesbian/same-gender loving woman. Forty-two percent of participants reported completing some college or receiving a 2-year college degree. Fifty percent of participants were employed either full or part time, and 39\% reported being unemployed or unable to work. Forty-one percent of participants reported an annual gross income of less than $\$ 29,000$.

Table 1 Demographics of Individual Interview $(n=22)$ and Focus Group Participants $(n=17)$

\begin{tabular}{|c|c|c|c|}
\hline & Individual interviews $n(\%)$ & Focus groups $n(\%)$ & Total $n(\%)$ \\
\hline Age* (mean, years) & 31 & 32 & 32 \\
\hline $18-34$ & $11(73)$ & $11(69)$ & $22(71)$ \\
\hline $35-44$ & $2(13)$ & $3(19)$ & $5(16)$ \\
\hline $45-54$ & $2(13)$ & 0 & $2(6)$ \\
\hline $55-64$ & 0 & $2(12)$ & $2(6)$ \\
\hline \multicolumn{4}{|l|}{ Gender } \\
\hline Male-to-female/transgender female & $10(45)$ & $16(94)$ & $26(67)$ \\
\hline Female-to-male/transgender male & $6(27)$ & 0 & $6(15)$ \\
\hline Genderqueer (neither exclusively male or female) & $5(23)$ & $1(6)$ & $6(15)$ \\
\hline Other & $1(5)$ & 0 & $1(3)$ \\
\hline \multicolumn{4}{|l|}{ Race/ethnicity } \\
\hline Black or African-American & $8(36)$ & $13(76)$ & $21(54)$ \\
\hline Latinx/Hispanic & $6(27)$ & $1(6)$ & $7(18)$ \\
\hline Asian/Asian American/Pacific Islander & $5(23)$ & $1(6)$ & $6(15)$ \\
\hline Multi-race & $3(14)$ & $2(12)$ & $5(13)$ \\
\hline \multicolumn{4}{|l|}{ Sexual orientation } \\
\hline Straight/heterosexual & $9(41)$ & $3(18)$ & $12(31)$ \\
\hline Gay or same-gender loving man & $3(14)$ & $6(35)$ & $9(23)$ \\
\hline Lesbian or same-gender loving woman & $1(5)$ & 0 & $1(3)$ \\
\hline Bisexual, pansexual, or queer & $8(36)$ & $5(29)$ & $13(33)$ \\
\hline Other 1 & $1(5)$ & $3(18)$ & $4(10)$ \\
\hline \multicolumn{4}{|l|}{ Education level $^{\dagger}$} \\
\hline Less than high school & $1(5)$ & $6(35)$ & $7(18)$ \\
\hline High school graduate or general equivalency diploma & $3(14)$ & $3(18)$ & $6(16)$ \\
\hline Some college or 2-year degree & $10(48)$ & $6(35)$ & $16(42)$ \\
\hline Bachelor's degree or more & $7(33)$ & $2(12)$ & $9(24)$ \\
\hline \multicolumn{4}{|l|}{ Employment status } \\
\hline Retired & 0 & $1(6)$ & $1(3)$ \\
\hline Unable to work or not employed & $7(33)$ & $8(47)$ & $15(39)$ \\
\hline Employed (part and full time) & $13(62)$ & $6(35)$ & $19(50)$ \\
\hline Student & $1(5)$ & $2(12)$ & $3(8)$ \\
\hline \multicolumn{4}{|l|}{ Annual individual income } \\
\hline Less than $\$ 10,000$ & $6(27)$ & $10(59)$ & $16(41)$ \\
\hline$\$ 10,000$ to $\$ 29,000$ & $8(36)$ & $4(24)$ & $12(31)$ \\
\hline$\$ 30,000$ to $\$ 49,000$ & $6(27)$ & $3(18)$ & $9(23)$ \\
\hline Greater than $\$ 50,000$ & $2(10)$ & 0 & $2(5)$ \\
\hline
\end{tabular}

*8 participants preferred not to provide their age

One individual interview participant preferred not to provide their education level

Fne individual interview participant preferred not to provide their employment status 
Table 2 Themes from Healthcare Experiences of Transgender People of Color Participants

\begin{tabular}{|c|c|c|}
\hline Major theme & Individual interview participants & Focus group participants \\
\hline $\begin{array}{l}\text { Different treatment } \\
\text { based on race }\end{array}$ & $\begin{array}{l}\text { "I think it would be just the authority with which you would } \\
\text { have over your whole world but also certainly your own body } \\
\text { and your own self, is something that is really only given to } \\
\text { white people." (Latinx transgender man) } \\
\text { "Whiteness in general carries a certain amount of benefit of } \\
\text { the doubt. So I think there would be less doubt about the } \\
\text { validity of my identity in general." (Latinx masculine gender } \\
\text { nonconforming person) }\end{array}$ & $\begin{array}{l}\text { "You have more of a positive image tied to you as a white } \\
\text { trans person than a black trans person.., because of how } \\
\text { black trans people are portrayed so often. We're always } \\
\text { seen as like the worst possible versions of ourselves." } \\
\text { (Black transgender woman) } \\
\text { "At the end of the day, they are going to still judge me. } \\
\text { They're going to look at my skin tone, and they going to } \\
\text { see that I'm black." (transgender woman) }\end{array}$ \\
\hline $\begin{array}{l}\text { Different treatment } \\
\text { based on gender } \\
\text { identity }\end{array}$ & $\begin{array}{l}\text { When asked if gender identity or race has a bigger impact on } \\
\text { treatment: "Being trans is the biggest factor. Sometimes I'm } \\
\text { in this battle with myself like, am I a Latina transsexual? Or } \\
\text { do I consider myself a transsexual Latina? What is the biggest } \\
\text { part of me? And I think the part that is most affected by } \\
\text { everything is the fact that I'm a transsexual." (Latinx }\end{array}$ & $\begin{array}{l}\text { "If I opened my legs and said, "Can you look at this?" and } \\
\text { I had a vagina, they would not care. It would be like } \\
\text { nothing ... That's the only thing that's stopping pretty } \\
\text { much a lot of us, because of what's between our legs." } \\
\text { (transgender woman) }\end{array}$ \\
\hline
\end{tabular}

Providers' stereotypes about TPOC

Respect for gender identity in healthcare settings

Healthcare agency preference

Preferences about providers everything is the fact that I'm a transsexual." (Latinx transgender woman)

"A lot of them go right into assuming that all of us have HIV [laugh]. That is the first, either it's that, or you have a transmitted disease." (Black transgender woman)

"She told me she was uncomfortable with me as a human being." (Latinx transgender woman)

"They always direct you as who you are. They always use the pronoun, names without any questions asked." (Black transgender woman)

"Now since I have insurance, and I go to LGBTQ clinics, then the treatment is very different. It is more for me. It feels safer." (Latinx transgender woman)

"I do not care if you are black, white, or whatever. As long as you understand the trials and tribulations of the trans woman of color, I'm cool with you" (Latinx transgender woman). "Do I want a male or female? Do I want them to be Hispanic, white or African-American? And I guess it all depends on how I am feeling that I will choose or I will prefer a certain race. If I am having a bad experience with my community, then I will say let me go with a white provider." (Latinx transgender woman)
"Once they find out that you are trans too, after being black, that's when it's like, well shit hits the fan after that." (transgender woman)

"Even if you have the documentation, they still choose to call you a man, regardless." (transgender woman)

"It was never any disrespect, and they always ask you ... your pronouns." (transgender woman)

"I like force myself to endure more pain or more discomfort, because ... I want to wait until I can get somewhere where a doctor is going to call me by my name and gender me properly." (Black transgender woman) "I would not say that I necessarily need to have a doctor that looks like me. But it needs, I need to be able to have a provider that empathizes with that I'm a person of color and that I'm transgender and at the same time. That they do not, one does not cancel out the other." (transgender woman)

\section{Healthcare Experiences}

The focus groups repeated and reinforced themes present in the individual interviews; thus, the healthcare experiences from both will be presented together. Community forums generally validated these themes. Emergent themes and example quotes are presented in Table 2.

\section{Reports of Inferior Healthcare Experiences}

All participants (100\%) described healthcare experiences that were negatively impacted because of provider responses to their race and/or gender identity. A majority of individual interview participants $(n=13)$ believed they would be treated better if they were cisgender people of color, rather than TPOC. When asked if they would be treated better if they were white and transgender, a majority of individual participants $(n=12)$ responded affirmatively. Participants in the focus groups echoed these sentiments (Table 2).

\section{Perceptions of Inferior Care in Response to the Participants' Race/Ethnicity, Sexual Orientation, and Gender Identity}

According to the quantitative survey responses, $38 \%$ of participants reported that healthcare professionals provided worse (inferior) care to them than other patients. Among the participants that reported receiving worse care, 33\% attributed worse care to transphobia, $20 \%$ to racism, $20 \%$ to homophobia, $13 \%$ to a combination of all three of these prejudices, $7 \%$ to both homophobia and racism, and 7\% to other reasons not listed.

Individual interview of participants most commonly identified gender identity alone as the reason for inferior healthcare experiences $(n=15)$. A major element of these negative healthcare experiences was providers' refusal to respect their gender identity $(n=10)$, most often in the form of using incorrect names and pronouns (see Table 2). Participants also reported instances of providers specifically stating that they were uncomfortable treating transgender patients.

Eleven participants described inferior healthcare experiences affected by both race and gender identity together. One participant reported:

"As somebody with ... a Mexican last name and as a Mexican person, I think folks ... will raise their eyebrow about that, the fact that I'm bringing in a passport. Like, is this a cover up? Is this somebody who's like kind of using a false document? ... Which is funny because...my motivation to use it is actually about my gender identity!" (Latinx transgender man)

Seven participants described negative experiences predominately affected by their race alone. A transgender woman explained: 
"They may not be able to clock that I'm transgender until I'm being examined. But I can't turn off that I'm black, as I walk through the door."

\section{Providers' Stereotypes and Assumptions About TPOC}

Interview participants cited stereotypes or assumptions about TPOC made by providers $(n=9)$ as a common factor in negative healthcare interactions. These stereotypes included provider's presumptions about patients' HIV status, drug use, sexual activity, and involvement in sex trafficking.

"My provider would make assumptions about me just because of my race and my, being transgender. Like, "Oh, so are you a sex worker? Are you this, are you that?" (Black transgender woman)

Other participants also described encountering stereotypes of TPOC; however, they believed these assumptions were more closely associated with their race as opposed to their gender identity.

"I think there's a lot of assumptions made about people of color and then again, just like trans people of color, who, that they're somehow like less educated, less resourceful, less resourced, less supported, than their white counterparts." (Latinx transgender man)

A minority of participants $(n=4)$ believed that stereotypes related to race did not affect their interactions with healthcare providers.

"I've never had a person disrespect me over the color of my skin ... Any healthcare provider that I went to, I just went. I just never thought of color or race." (Black transgender woman)

\section{Searching for Healthcare Locations: Provider Cultural Competence and Intersectional Identities}

Eighty-two percent of the quantitative survey participants reported actively seeking out LGBT-friendly healthcare professionals (providers known to serve LGBT patients well or providers working in settings that explicitly aim to care for LGBT people). Many interview participants were more likely to describe positive experiences in LGBT-friendly healthcare settings ( $n=7$, see Table 2$)$. However, one interview participant felt that their racial/ethnic identity was not affirmed in these settings.

"When we're talking about racial stuff, there's still a little bit of divide there ... If I walk into a room of black trans women, and a white trans woman walks into the room ... we showed up differently." (Black transgender woman)

\section{Provider Identity and Cultural Competence Serving TPOC}

In the quantitative survey, $36 \%$ of participants reported actively seeking out healthcare professionals who match their own race or ethnicity. In the qualitative interviews, participants $(n=8)$ expressed their preference for having a provider of color, citing a more authentic connection and greater empathy compared with white providers. One participant explained:

"You feel like you can be yourself. You can be whoever you want to be ... You don't have to hide from nobody. You don't have to sit there and act like somebody you're not." (Black transgender woman)

However, one participant voiced apprehension about disclosing their gender identity to providers of color due to their fear of transphobia.

"There's a lot of internalized feeling about what our brown communities do or don't accept. I think oftentimes they're based on internalized racism that I recognize, but I think that it does tend to make me less likely to disclose because I want...it's so rare to have a provider that's a person of color that I fear alienating that person, so it feels easier to just pass and maybe connect with that person from that one identity and wait to see how safe it is before disclosing the other identity." (Latinx masculine gender-nonconforming person)

When asked about the importance of having an LGBTQ physician, one participant identified a preference for a physician who identified as transgender as opposed to lesbian or gay physicians:

"Preferably T (transgender). The Ls (lesbians) and the Gs (gays) can be just as ignorant about the transgender things." (multiracial genderqueer person)

Four participants reported that they prioritized a provider's knowledge about trans-related healthcare over their other identities due to limited options.

"My trans care kind of trumps my need to seek a provider that is Latinx, because ... I mean, ideally, right, it would be like a trans Latinx queer person [laugh] that could be a provider for something. And that's not any provider I've ever met." (Latinx transgender man)

\section{Positive Healthcare Experiences and Respect for Gender Identity}

Individual interview participants most frequently mentioned gender identity alone when describing positive healthcare experiences $(n=15)$ and the most common example they described was a provider's respect for their gender identity in the form of using the participant's correct name and pronouns $(n=13$, see Table 2$)$.

A minority of participants described positive experiences that were impacted by both their race and gender identity together $(n=6)$.

"She (healthcare provider) knew that top surgery was also different for white people versus people of color. She actually went and had examples and photos to show me about how scars might look different or how healing might look different, which never in a healthcare experience have I even had a doctor, a white doctor specifically, who is aware of how that might be different for me and actually gave me advice about that." (Latinx masculine gender-nonconforming person) 


\section{DISCUSSION}

Our study shows that TPOC face discrimination based on both gender identity and race in healthcare settings. Thus, this population has unique and arguably more challenging healthcare experiences compared with their white transgender or cisgender racial/ethnic minority counterparts. Among the $38 \%$ of participants that reported receiving inferior care compared with other patients, transphobia and racism were both listed as causative factors with similar frequency. In addition, many participants described how both of these causative factors often present simultaneously and result in negative healthcare experiences that are different compared with either type of discrimination experienced in isolation.

Participants were less likely to provide specific examples of racism in the qualitative interviews and focus groups, especially compared with the numerous examples in which they described providers' overt transphobia. Patients seeking care for their transgender healthcare needs, such as genderaffirming hormone therapies, are in a particularly sensitive, vulnerable situation where disclosure of gender identity to the provider is necessary. Thus, examples of transphobia in healthcare experiences may be more salient to participants than racism, which is commonly seen across most, if not all, environments.

Participants juggle provider preferences and the disclosure of their identities in ways that their white transgender or cisgender racial/ethnic counterparts do not. While a notable portion of participants reported seeking out providers of color, participants also voiced reservations about gender identity disclosure to providers of color due to their fear of transphobia. Some participants spoke to an internal risk/benefit analysis they conducted weighing their valuable relationship with a provider of color against their fear of a negative reaction to gender identity disclosure. Studies have shown dual minorities with a more integrated identity have higher levels of overall well-being and health-promoting behaviors. ${ }^{13,} 23$ The participants' discussion of their relationship with racially concordant providers highlights how maintaining an integrated identity can be challenging for TPOC. Research has shown that race concordance between patients and physicians is associated with higher patient satisfaction and enhanced communication; however, the positive impact of race concordance between TPOC and providers of color may be moderated if TPOC fear transphobia. ${ }^{24}$

Many of the major themes from the in-depth interviews and focus groups of TPOC reiterate results of previous studies of predominantly white transgender populations. ${ }^{1,4}$ Characteristics of positive clinical encounters described by participants included providers who demonstrated their respect for participants' gender identity by using the correct name and pronouns, and who were knowledgeable about transgender healthcare. However, the experiences described by our study participants should inspire healthcare providers and organizations to go beyond these basic competencies. There is a need for diversity and inclusion programming and quality improvement activities that specifically address the provision of competent and high-quality care to patients who hold multiple minority identities. Cook et al. (2017) and DeMeester et al. (2016) provide numerous strategies, recommendations, and examples for healthcare organizations striving to improve the quality of care they provide to people of color who also hold sexual and gender minority identities. ${ }^{11,25}$

Our study has several limitations. All of our study's participants were residents of Chicago, a densely populated urban area. Research has shown that rural transgender populations face higher levels of stigma and reduced access to primary care. Therefore, our findings may not reflect the experience of TPOC living outside urban locales. ${ }^{26}$ The young average age of our sample also limits generalizability given that elderly transgender people face additional unique challenges. ${ }^{27} \mathrm{In}$ addition, due to sample size, the experiences of an extremely diverse sample with regard to gender identities and racial/ ethnic minority groups were often presented as a monolithic group, which could obscure important differences across these demographics.

Both race and gender identity affect how TPOC receive care. Sometimes race or gender identity is the dominant factor impacting the healthcare experience, but the healthcare experiences of TPOC reflect the intersectional effects of multiple concurrent identities. We must improve the quality of care delivered to TPOC to address the health disparities suffered by this population.

Acknowledgments: Morten Group recruited and interviewed participants. Pride Action Tank, a project of the AIDS Foundation of Chicago, kindly hosted our community feedback session.

Corresponding Author: Susanna D. Howard, MD; , Section of General Internal Medicine, University of Chicago, Chicago, IL, USA (e-mail: susanna.howard@uchospitals.edu).

Funding Information This project was financially supported by the Agency for Healthcare Research and Quality (IU18 HSO23050), and NIH CTSA UL1 TRO00430. Dr. Chin was supported in part by the Chicago Center for Diabetes Translation Research (NIDDK P3O DK092949). Susanna Howard was supported in part by NIH NIDDK grant no. T35DK062719-29.

\section{Compliance with Ethical Standards:}

This study was approved by the University of Chicago Biological Sciences Division Institutional Review Board.

Conflict of Interest: The authors declare that they do not have a conflict of interest.

\section{REFERENCES}

1. Grant JM, Mottet LA, Tani J, Harrison J, Herman JL, Keisling M. Injustice at every turn: a report of the national transgender discrimination survey. Washington, DC: National Center for Transgender Equality and National Gay and Lesbian Task Force (US); 2011.

2. James SE, Herman JL, Rankin S, Keisling M, Mottet L, Anafi M. The report of the 2015 U.S. transgender survey. Washington, DC: National Center for Transgender Equality (US); 2016. 
3. Sugano E, Nemoto T, Operario D. The impact of exposure to transphobia on HIV risk behavior in a sample of transgendered women of color in San Francisco. AIDS Behav. 2006;10:217-225.

4. Bradford J, Reisner SL, Honnold JA, Xavier J. Experiences of transgender-related discrimination and implications for health: results from the Virginia Transgender Health Initiative Study. Am J Public Health. 2013;103:1820-1829.

5. Geiger HJ. Health disparities: what do we know? what do we need to know? What should we do?. In: Schulz AJ, Mullings L, eds. Gender, race, class, and health: intersectional approaches. San Francisco: Jossey Base; 2006. p. 261-288.

6. van Ryn M. Research on the provider contribution to race-ethnicity disparities in medical care. Med Care. 2002;40:I140-151.

7. Schulman KA, Berlin JA, Harless W, et al. The effect of race and sex on physicians' recommendations for cardiac catheterization. N Engl J Med. 1999;340:618-626.

8. Grollman EA. Multiple disadvantaged statuses and health: the role of multiple forms of discrimination. J Health Soc Behav. 2014;55:3-19.

9. Tan JY, Baig AA, Chin MH. High stakes for the health of sexual and gender minority patients of color. J Gen Intern Med. 2017;32:1390-1395.

10. Wilson EC, Arayasirikul S, Johnson K. Access to HIV care and support services for African American transwomen living with HIV. Int $\mathrm{J}$ Transgend. 2013;14:182-195.

11. Cook SC, Gunter KE, Lopez FY. Establishing effective health care partnerships with sexual and gender minority patients: recommendations for obstetrician gynecologists. Semin Reprod Med. 2017;35:397407

12. Eckstrand KL, Eliason $\mathbf{J}$, St Cloud T, Potter J. The priority of intersectionality in academic medicine. Acad Med. 2016;91:904-907.

13. Peek ME, Lopez FY, Williams HS et al. Development of a conceptual framework for understanding shared decision making among AfricanAmerican LGBT patients and their clinicians. J Gen Intern Med. 2016; 31: 677-687.

14. Purdie-Vaughns V, Eibach RP. Intersectional invisibility: the distinctive advantages and disadvantages of multiple subordinate-group identities. Sex Roles. 2008; 59: 377-391.

15. Tan JY, Xu LJ, Lopez FY, et al. Shared decision making among clinicians and Asian American and Pacific Islander sexual and gender minorities: an intersectional approach to address a critical care gap. LGBT Health. 2016;3:327-334.
16. Baig AA, Lopez FY, DeMeester RH, Jia JL, Peek ME, Vela MB. Addressing barriers to shared decision making among Latino LGBTQ patients and healthcare providers in clinical settings. LGBT Health. 2016;3:335-341.

17. Chin MH, Lopez FY, Nathan AG, Cook SC. Improving shared decision making with LGBT racial and ethnic minority patients. J Gen Intern Med. 2016;31:591-593.

18. Bornstein DR, Fawcett J, Sullivan M, Senturia KD, Shiu-Thornton S. Understanding the experiences of lesbian, bisexual and trans survivors of domestic violence. J Homosex. 2006;51:159-181.

19. Miles MB, Huberman AM. Qualitative data analysis: An expanded sourcebook. Thousand Oaks, CA: Sage Publications; 1994.

20. Morgan DL. Focus groups as qualitative research. Thousand Oaks: Sage Publications; 1997.

21. Strauss AL. Qualitative Analysis for Social Scientists. New York: Cambridge University Press; 1987.

22. Morse JM, Richards L, Richards $\mathbf{L}$. Read me first for a user's guide to qualitative methods. Thousand Oaks: Sage Publications; 2002.

23. Crawford I, Allison KW, Zamboni BD, Soto T. The influence of dualidentity development on the psychosocial functioning of AfricanAmerican gay and bisexual men. J Sex Res. 2002;39:179-189.

24. Cooper LA, Roter DL, Johnson RL, Ford DE, Steinwachs DM, Powe NR. Patient-centered communication, ratings of care, and concordance of patient and physician race. Ann Intern Med. 2003;139:907-915.

25. DeMeester RH, Lopez FY, Moore JE, Cook SC, Chin MH. A model of organizational context and shared decision making: application to LGBT racial and ethnic minority patients. J Gen Intern Med. 2016;31:651-662.

26. Whitehead $\mathbf{J}$, Shaver $\mathbf{J}$, Stephenson $\mathbf{R}$. Outness, stigma, and primary health care utilization among rural LGBT populations. PLoS One. 2016;11:e0146139.

27. Ettner R. Care of the elderly transgender patient. Curr Opin Endocrinol Diabetes Obes. 2013;20:580-584.

Publisher's Note Springer Nature remains neutral with regard to jurisdictional claims in published maps and institutional affiliations. 